\title{
Framing Social and Emotional Learning among African-American Youth: Toward an Integrity-Based Approach
}

\author{
Robert J. Jagers \\ University of Michigan School of Education, Ann Arbor, Mich., USA
}

This essay offers a cursory analysis of the potential of social and emotional learning (SEL) to foster optimal growth among African-American youth. Over the past two decades, the field of SEL has come to encompass a range of programs and practices that promote core social and emotional competencies (e.g., self-awareness, selfmanagement, social awareness, relationship skills, and responsible decision-making) in schools and communities to support desired developmental outcomes [Durlak, Domitrovich, Weissberg, \& Gullotta, 2015]. The field has appropriately garnered interest from a variety of stakeholders who share a commitment to improving such outcomes for children and youth from diverse backgrounds.

Given the statuses and strivings of African-American youth, it is essential to interrogate more deeply whether and in what ways SEL can be leveraged to advance their personal and collective well-being. Despite notable successes in politics, business, education, and entertainment, research on the African-American experience tends to highlight vulnerabilities and inequities in educational, economic, criminal justice, and health-related processes and outcomes. These conditions have helped reinvigorate public debate and stimulated an uptick in civic organizing and activism.

An integrity-based perspective is useful to this analysis as it situates the presentday African-American experience within the larger history of racialized cultural oppression that often accompanies American global imperialism. However, this perspective foregrounds the resulting resistance and pursuit of self-determined wellness by people of color throughout the world [Jagers, Mustafaa, \& Noel, in press]. The recent protests and organizing triggered by both police and internecine violence represent contemporary instantiations of this centuries-old struggle. There is an appreciation for connections with other domestic and international movements (often youth led) that have (re)emerged to counter related concerns, such as Angloconformity and rising xenophobia, corporatism and government dysfunction, exploitation of women and heteronormativity, militarized police tactics and protracted foreign wars, and environmental exploitation and climate change.

\begin{tabular}{ll}
\hline KARGER & ○ 2016 S. Karger AG, Basel \\
E-Mail karger@karger.com & $0018-716 \mathrm{X} / 16 / 0591-0001 \$ 39.50 / 0$ \\
www.karger.com/hde &
\end{tabular}

\author{
Robert J. Jagers \\ University of Michigan School of Education \\ 610 East University Avenue, Room 2339 \\ Ann Arbor, MI 48109 (USA) \\ E-Mail rjagers@umich.edu
}


As a result, SEL work can be understood with regard to what ways it advances resistance to oppression and collective well-being for a range of disenfranchised groups. Briefly, oppression entails a state of asymmetric power relations characterized by domination and subordination, such that dominating persons or groups exercise their power to restrict access to material resources and convince both the dominant and subordinated groups that such arrangements are justified. Resistance can lead to freedom to determine, pursue, and attain collective economic, educational, and health-related well-being.

Resistance to oppression can be self-defeating, reactionary, conformist, and/or transformational [Solorzano \& Delgado-Bernal, 2001]. Pivotal considerations among these are the degree and nature of one's critique of existing social arrangements and the striving for social justice. Reactionary and self-defeating forms of resistance differ slightly with regard to the level of system critique, but neither is motivated by social justice. Conformist resistance offers no, or limited system critique and is motivated by self-serving justice (access) within the existing social order. On the other hand, transformational resistance features a system critique and is motivated by social justice.

With regard to African-American youth, this framing must illuminate patterns of race/ethnic relations, types of citizenship, and the nature of adult/youth relations being advanced. Racial/ethnic relations are important due to the contradictions inherent in US democratic aspirations and the continued conflation of race, class, and culture. Some possibilities include variants of assimilation, pluralism, separatism, and system change (reform/revolution). Forms of citizenship can emphasize personal responsibility for behaving in prosocial ways (e.g., helping and cooperating), active participation to sustain existing social institutions, or social activism geared toward a more equitable and just system for all [Westheimer \& Kahne, 2004]. Finally, voice and control are key dimensions of adult/youth relations, which can range from youth as vessel (youth have no voice or control) to plural (youth and adults have voice and share control) to autonomous (youth have voice and full control) [Wong, Zimmerman, \& Parker, 2010].

Applying this analytic frame to extant SEL programs, risk prevention/reduction programs targeting problem behaviors (e.g., school dropout, violence, substance use, obesity and/or unsafe sex) can be seen as minimizing, self-defeating, reactionary, resistance behaviors. Such programs reflect a prevention science approach that emerged in the context of the war on drugs and a spate of school shootings. These programs can employ cultural adaptations, but focus primarily on student's social problemsolving and refusal skills with little to no attention paid to broader societal conditions that place youth at elevated risk for problem behaviors. As a result, such programs are consistent with assimilation, personally responsible citizenship, and the youth as vessel framework.

Competence and resilience promotion programs correspond with conformist resistance. These programs often reflect the shift toward creating contexts that foster youth assets and address developmental needs. Youth councils, democratic classroom practices, multicultural education, and service learning are examples of programs of this sort. While these efforts can foster inclusion, they typically lack explicit attention to racial and class inequities in school or the broader society. As a result, such programs promote assimilation, participatory citizenship, and symbolic (voice and no choice) youth involvement.

2

Human Development 2016;59:1-3 DOI: $10.1159 / 000447005$ 
Resistance facilitation programs foster transformational resistance. For example, approaches such as culturally responsive and sustaining pedagogy and youth participatory action research seek to counteract the tendency toward social reproduction in schools and society by encouraging critical social analysis, collective efficacy, and collective action [Watts \& Hipolito-Delgado, 2015]. Young people are positioned as experts in understanding and fashioning a world that is more just and equitable. These strategies allow for adult-youth relations that are pluralistic or autonomous, and contribute to justice-oriented citizenship. The resulting racial/ethnic relations can be plural or system changing in nature.

In sum, as the field of social and emotional learning evolves, it is imperative to be clear about the implications of specific approaches for youth development processes and outcomes, especially for youth from historically disenfranchised and underresourced backgrounds. This analysis will be further developed to aid stakeholders in better aligning imagined forms of US democracy and extant youth characteristics with SEL program goals, content, delivery, and assessments. This level of calibration can help position diverse youth to optimize their respective contributions to collective well-being in school, community, and global contexts.

\section{References}

Durlak, J.A., Domitrovich, C.E., Weissberg, R.P., \& Gullotta, T.P. (Eds.) (2015). Handbook of social and emotional learning: Research and practice. New York, NY: Guilford Press.

Jagers, R.J., Mustafaa, F.N, \& Noel, B. (in press). Cultural integrity and African American empowerment: Insights and practical implications for community psychology. In M.A. Bond, C.B. Keys \& I. Serrano-García (Eds.), Handbook of community psychology (vol. 2). Washington, DC: American Psychological Association.

Solorzano, D.G., \& Delgado-Bernal, D. (2001). Examining transformational resistance through a critical race and LatCrit theory framework: Chicana and Chicano students in an urban context. Urban Education, 36, 308-342. doi:10.1177/0042085901363002

Watts, R.J., \& Hipolito-Delgado, C.P. (2015). Thinking ourselves to liberation? Advancing sociopolitical action in critical consciousness. Urban Review, 47, 847-867. doi:10.1007/s11256-015-0341-x

Westheimer, J., \& Kahne, J. (2004). What kind of citizen? The politics of educating for democracy. American Educational Research Journal, 41, 237-269. doi:10.3102/00028312041002237

Wong, N.T., Zimmerman, M.A., \& Parker, E.A. (2010). A typology of youth participation and empowerment for child and adolescent health promotion. American Journal of Community Psychology, 46, 100-114. doi:10.1007/s10464-010-9330-0 